\title{
PERÍODOS DE REFRIGERAÇÃO ANTECEDENDO O ARMAZENAMENTO SOB ATMOSFERA CONTROLADA NA CONSERVAÇÃO DE CAQUI 'FUYU'
}

\author{
Periods of cold preceding the storage in controlled atmosphere \\ in the conservation of 'Fuyu' persimmon \\ Carlos Roberto Martins ${ }^{1}$, César Luiz Girardi ${ }^{2}$, Adriana Regina Corrent ${ }^{3}$, \\ Paula Guerra Schenato ${ }^{4}$, Cesar Valmor Rombaldi ${ }^{5}$
}

\begin{abstract}
RESUMO
Com o presente trabalho objetivou-se avaliar o efeito de diferentes períodos de refrigeração antecedendo a implantação da atmosfera controlada (AC) sobre a qualidade e conservação pós-colheita de caquis, cv. Fuyu (Diospyrus kaki L.). Foram utilizadas frutas provenientes de um pomar comercial de Caxias do Sul-RS, colhidas com coloração amarelo-alaranjada, na safra de 2002. O processo de resfriamento foi realizado em câmara frigorífica comercial, com temperatura de $0 \pm 0,5^{\circ} \mathrm{C}$ e $95 \pm 3 \%$ de UR, por períodos de 24, 48 e 72 horas, antes do estabelecimento das condições de $\mathrm{AC}\left(8 \%\right.$ de $\mathrm{CO}_{2}$ e $2 \%$ de $\left.\mathrm{O}_{2}\right)$. As avaliações foram realizadas na colheita aos $7,14,21,28,35$ e 42 dias de armazenagem em atmosfera controlada, mais três dias de simulação de comercialização $\left(20 \pm 3^{\circ} \mathrm{C}, 75 \pm 5 \%\right.$ UR). As frutas com 48 horas de refrigeração mantiveram menor evolução da coloração da epiderme ao longo do armazenamento. O teor de SST, a firmeza de polpa e o escurecimento da epiderme não foram influenciados pelos períodos de resfriamento. A qualidade e conservação pós-colheita das frutas não foram influenciadas pelos diferentes períodos de refrigeração antes de serem armazenadas em AC.
\end{abstract}

Termos para indexação: Pós-colheita, escurecimento, armazenamento, Diospyros kaki.

\section{SUMMARY}

The objective of this work was to evaluate the effect of different periods of refrigeration preceding the establishment of controlled atmosphere (CA), on the postharvest quality and conservation of 'Fuyu' persimmon (Diospyrus kaki L.). Fruits from a commercial orchard located in Caxias do Sul-RS, harvested in 2002, were collected at the yellow-orange skin color stage. The cooling process was applied at a commercial chamber with $0 \pm 0.5^{\circ} \mathrm{C}$ and $95 \pm 3 \% \mathrm{RU}$, for periods of 24,48 and 72 hours, before the establishment of the CA conditions $\left(8 \% \mathrm{CO}_{2}\right.$ and $\left.2 \% \mathrm{O}_{2}\right)$. The fruits were evaluated at the harvest, and on the $7^{\text {th }}, 14^{\text {th }}, 21^{\text {st }}, 28^{\text {th }}, 35^{\text {th }}$ and $42^{\text {nd }}$ days in controlled atmosphere, followed by three days of shelf-life $\left(20 \pm 3{ }^{\circ} \mathrm{C}, 75 \pm 5 \% \mathrm{RU}\right)$. The fruits refrigerated for 48 hours showed poor evolution on the skin color during storage. In SST content, pulp firmness and skin browning were not influenced by any cooling period. The postharvest conservation and quality of the fruits were not influenced by the different periods of refrigeration before stored in AC.

Index terms: Postharvest, skin browning, storage, Diospyros kaki.

(Recebido para publicação em 3 de outubro de 2003 e aprovado em 11 de março de 2004)

\section{INTRODUÇÃO}

Nessa última década, ocorreu acréscimo nas áreas cultivadas e na produção de caquis (Dyospyros kaki L.), principalmente pela implantação de pomares com cultivares não-taninosas, como o Fuyu, o que impulsionou a abertura de novos mercados. A excelente aceitabilidade dessa fruta deve-se à sua boa apa rência, ao tamanho médio a grande e à polpa amareloavermelhada, de textura firme, sabor adocicado e baixa acidez. Aliado a isso, é uma fruta com relativa facilidade de manejo no pomar, demandando pouca mão-de-obra.

Tendo em vista a concentração da colheita entre abril e julho e a elevação do preço após a safra, os pro-

\footnotetext{
1. Engenheiro Agrônomo, MSc, Doutorando em Pós-Graduação em Agronomia, UFPel - Rua Monte Caseros, 3113, Centro - $97510-380$ - Pelotas, marticar@ufpel.tche.br

2. Engenheiro Agrônomo, Msc., Pesquisador da Embrapa Uva e Vinho - Caixa Postal 130 - 95700-000 - Bento Gonçalves, RS. girardi@cnpuv.embrapa.br 3. Engenheiro Agrônomo, Mestranda de Pós-Graduação em Ciência e Tecnologia Agroindustrial - UFPel.

4. Acadêmica de Biologia da UCS/CARVI de Bento Gonçalves, RS.

5. Engenheiro Agrônomo, PhD. Professor, DCTA/FAEM/UFPel, Caixa Postal 354 - 96001-970 - Pelotas, RS.
} 
dutores estão armazenando as frutas para obterem melhores preços de comercialização. No entanto, o prolongamento do período de refrigeração dos caquis depende do ponto de maturação, cultivar e condições de armazenamento. $\mathrm{O}$ armazenamento refrigerado (AR) pode conservar caquis cv. Fuyu em condições ótimas de comercialização por até 30 dias (RINALDI et al., 1998). O armazenamento de caquis em atmosfera modificada apresenta grande variabilidade de resultados, mas em muitos trabalhos verifica-se como período seguro de 30 a 90 dias, dependendo do tipo de embalagem, espessura e acondicionamento (KAWADA, 1982; MACRAE, 1987; BEN-ARIE e ZUTKHI, 1992; NEVES, 2002). Em relação ao armazenamento em atmosfera controlada dessa fruta, poucos são os trabalhos realizados. Brackmann e Saquet (1995) constataram que o armazenamento em temperatura de $0^{\circ} \mathrm{C}$ com $8 \%$ de $\mathrm{CO}_{2}$ e $2 \%$ de $\mathrm{O}_{2}$ mantiveram os frutos da cv. Fuyu por, no mínimo, de 3 meses em $\mathrm{AC}$ e mais 4 dias à temperatura ambiente. Porém, o emprego de $\mathrm{AC}$ ainda é limitado pelo alto valor de investimento inicial e, principalmente, pela falta de informações sobre o comportamento e armazenamento de caquis nessas condições.

Mesmo assim, alguns produtores vêm utilizando o armazenamento em AC. Uma preocupação constante diz respeito à operacionalização das câmaras frias e ao estabelecimento das condições de concentrações dos gases $\mathrm{CO}_{2}$ e $\mathrm{O}_{2}$. Diante das condições adversas de colheita das frutas, muitas vezes, não é possível efetuar a colheita e colocá-las rapidamente em condições de atmosfera controlada, pois as câmaras comerciais são de grande porte, em geral, acima de 200 toneladas. É necessário um maior período para proceder ao fechamento das câmaras e ao estabelecimento da AC, período em que as frutas são submetidas ao frio da armazenagem refrigerada.

Dentro desse contexto, com o presente trabalho teve-se como objetivo avaliar o comportamento de caquis submetidos a três períodos de refrigeração antecedendo o armazenamento em atmosfera controlada e a influência desses períodos na qualidade e conservabilidade pós-colheita dessa espécie.

\section{MATERIAL E MÉTODOS}

Caquis da cultivar Fuyu foram colhidos com a coloração da casca amarelo-alaranjada em um pomar comercial no município de Caxias do Sul-RS. Imediatamente após cada colheita, os frutos foram selecionados, eliminando-se aqueles com defeito e padronizando os outros quanto ao estádio de maturação, com base na coloração da casca. Logo após essa etapa, as frutas foram submetidas a 24,48 e 72 horas de refrigeração $\left(0^{\circ} \mathrm{C} \pm 0,5^{\circ} \mathrm{C}\right.$ e umidade relativa de $\left.95 \pm 3 \%\right)$, em câmara comercial com capacidade para 120 toneladas. Após esses períodos, as frutas foram submetidas às mesmas condições de refrigeração com o estabelecimento da AC, modificando a concentração dos gases para $8 \%$ de $\mathrm{CO}_{2}$ e $2 \%$ de $\mathrm{O}_{2}$, seguindo a recomendação para cultivar e região (BRACKMANN e DONAZZOLO, 2000).

Para o acompanhamento da conservação e qualidade dos caquis, foram utilizadas três repetições por tratamento, sendo cada repetição composta de 10 frutos. As avaliações foram realizadas na instalação do experimento (colheita $=0$ dia) e aos 7, 14, 21, 28, 35 e 42 dias de armazenagem em atmosfera controlada, mais três dias de vida de prateleira $\left(20 \pm 3^{\circ} \mathrm{C}, 75 \pm 5 \%\right.$ UR $)$. Em todos os períodos, foram realizadas análises de coloração da casca, firmeza de polpa (FP), sólidos solúveis totais (SST), acidez total titulável (ATT) e nível de escurecimento da epiderme. Essas análises foram realizadas nos laboratórios de pós-colheita da Embrapa Uva e Vinho, de acordo com a seguinte metodologia: A) Cor da casca: foi obtida pela leitura do ponto representativo da coloração predominante da epiderme de cada fruta, antes de avaliar a firmeza de polpa, medida com um colorímetro Minolta CM-508d. No presente trabalho, serão apresentados apenas os valores $\mathrm{h}$, que relacionam os valores de a e b ( $\left.h=\operatorname{tg}^{-1} b / a\right)$. B) Escurecimento: foram atribuídas notas de acordo com escala visual de 0 a 10 , sendo $0=$ sem escurecimento; $1=$ de 1 a $10 \%$ de escurecimento; $2=$ de 11 a $20 \%$ de escurecimento e assim sucessivamente, até a nota $10=$ de 91 a $100 \%$ de escurecimento. Ressalta-se que não foram apresentadas nos resultados as notas 7,8,9 e 10, por não terem sido encontradas frutas com tais dimensões de escurecimento da epiderme. C) Firmeza da Polpa (FP): foi determinada com auxílio de um penetrômetro manual, munido de ponteira de $8 \mathrm{~mm}$, expressando-se os resultados em Newtons (N). Em cada fruto, foram realizadas 2 leituras, em lados diametralmente opostos, na seção equatorial do fruto após remoção da epiderme. Após essa etapa, os frutos foram descascadas, sendo retiradas duas fatias da polpa de cada fruto, em uma amostra constituída de 10 caquis, em lados diametralmente opostos. Com o auxílio de uma centrífuga doméstica, extraiu-se o suco para determinação de: D) Sólidos Solúveis Totais (SST), obtidos com auxílio de refratômetro manual, sendo os resultados expressos em ${ }^{\circ}$ Brix; E) Acidez Total Titulável (ATT), determinada por titulometria de neutralização com $\mathrm{NaOH} 0,1 \mathrm{~N}$ até pH 8,1, utilizando-se 10 
$\mathrm{mL}$ de suco, sendo os resultados expressos em Cmol. $\mathrm{L}^{-}$ 1 de suco;

$\mathrm{O}$ experimento foi conduzido em delineamento inteiramente casualizado, seguindo um esquema fatorial 3x6 (tratamentos x períodos) com 3 repetições. Para comparação de médias, foi utilizado o Teste de Tukey ao nível de $5 \%$ de probabilidade de erro.

\section{RESULTADOS E DISCUSSÃO}

Os frutos foram colhidos com firmeza de polpa média de $54 \mathrm{~N}$, SST $15,4^{\circ}$ Brix, ATT de 0,79 Cmol.L

${ }^{1}$ e com coloração de 58,17 para valores de h, o que designa frutas com coloração amarelo-alaranjada. Essas são as condições normalmente utilizadas para a colheita, estando dentro da faixa recomendada para a região (BRACKMANN et al., 1997; ROMBALDI, 1999).

Durante o período de armazenamento, os frutos apresentaram comportamento similar quanto à firmeza de polpa, que se reduziu à medida que avançou o período de conservação (Figura 1). Porém, a redução se procedeu de forma mais acentuada nos frutos que receberam apenas 24 horas de resfriamento, que ainda demonstraram uma maior variação da firmeza com os períodos de armazenamento. De uma forma geral, os diferentes períodos de frio que antecederam o armazenamento em AC não influenciaram a firmeza de polpa.

Os caquis submetidos a 24 horas de resfriamento apresentaram elevação da firmeza de polpa aos 35 dias de armazenamento, de aproximadamente $25 \mathrm{~N}$. A razão dessa variação ainda é desconhecida, porém, especulase que no período de simulação de comercialização houve queda acentuada da temperatura ambiente, o que pode ter influenciado de alguma forma o metabolismo das frutas com 24 horas de resfriamento. Após 42 dias de armazenamento em AC, os frutos não apresentavam mais condições de comercialização, independente do tratamento adotado. Em todos os frutos evidenciaram-se sintomas de escurecimento da epiderme, com forte odor de fruto fermentado e também com elevada porcentagem de frutos amolecidos. Vale ressaltar que, pela análise visual, todos os frutos apresentavam, já aos 28 dias de conservação, polpa com aspecto gelatinoso e com perda da suculência, interferindo nas condições de comercialização. Segundo MacRae (1987), o que mais limita o armazenamento de caquis é a ocorrência de distúrbios fisiológicos provocados pelo frio (chilling injury), sendo os sintomas relatados semelhantes aos encontrados neste experimento, ou seja, gelatinização da polpa e diminuição da suculência, mas sem perda excessiva da firmeza de polpa.

Além de dificultar o manuseio, transporte e comercialização, a diminuição da firmeza é um dos principais atributos de qualidade avaliados pelo consumidor (MITCHAM et al., 1998). Para que os caquis da cv. Fuyu tenham boa aceitabilidade para o consumo in natura, a firmeza de polpa deve ser superior a $20 \mathrm{~N}$ (BEM-ARIE, 1995; MITCHAM et al., 1998; ROMBALDI, 1999). Dentro desses parâmetros, somente os caquis submetidos a 48 e 72 horas de frio mantiveram um melhor padrão de firmeza durante 28 dias de conservação em AC.

Brackmann e Saquet (1995) observaram que caquis cv. Fuyu aramazenados em $\mathrm{AC}\left(8 \% \mathrm{CO}_{2}\right.$ e $\left.2 \% \mathrm{O}_{2}\right)$, ao final de 85 dias mais 5 dias de vida de prateleira, apresentavam-se firmes, com aproximadamente $33 \mathrm{~N}$. Uma possível explicação da não-constatação dos mesmos resultados obtidos por esses autores é que, primeiramente, o comportamento no armazenamento póscolheita dos frutos depende crucialmente das condições edafoclimáticas, qualidade das plantas, manejo do solo, práticas e tratos culturais, cultivar e manejo de irrigação (CRISOSTO et al., 1997), o que possivelmente pode ter influenciado nos resultados deste trabalho. No momento da colheita, os frutos apresentavam-se com baixa acidez, em torno de 0,79 $\mathrm{Cmol} \mathrm{L}^{-1}$. Esse resultado foi semelhante ao encontrado por Danieli (2000), que foi de 0,9 Cmol. L ${ }^{-1}$ e Ferri (2000), de 0,4 a 0,9 Cmol. L ${ }^{-1}$, com caquis da mesma região do presente experimento. Aos 7 dias, a ATT elevou-se em relação à avaliação na colheita, e a acidez de frutos submetidos a 72 horas de refrigeração foi significativamente superior à acidez dos frutos submetidos a 24 horas de refrigeração. Após esse período, a ATT sofreu uma pequena redução até o $28^{\circ}$ dia de armazenamento, voltando a elevar-se posteriormente. Os frutos submetidas a 48 horas de refrigeração apresentaram menor grau de variação no nível de acidez em relação aos demais tratamentos, apresentando ATT variável entre 1,30 a 1,90 Cmol.L ${ }^{-1}$. Helbig (1998), trabalhando com ameixas, relata um decréscimo inicial da ATT devido à diminuição do conteúdo de ácidos orgânicos em um primeiro momento. Posteriormente, a geração de radicais ácidos provenientes da hidrólise de componentes da parede celular proporciona elevação da ATT, observada pelos autores na fase final do armazenamento. Esses mesmos autores afirmam que isso ocorre paralelamente ao amolecimento dos frutos. Aos 14, 21 e 42 dias, as frutas submetidas a 24 horas de refrigeração apre- 
sentaram acidez significativamente superior aos demais tratamentos. Aos 35 dias de armazenamento os frutos submetidos a 72 horas de refrigeração apresentaram maior nível de acidez e, aos 28 dias, não foi constatada diferença significativa na acidez entre os tratamentos.

Apesar de haver uma diferença significativa no nível de ATT média dos tratamentos ao final dos 42 dias de armazenamento, os frutos que receberam 24 horas de refrigeração $\left(1,64 \mathrm{Cmol} . \mathrm{L}^{-1}\right)$, apresentaram valores muito próximos dos demais tratamentos (48 horas com 1,53 Cmol.L e 72 horas com 1,61 Cmol.L $\mathrm{C}^{-1}$ ), o que provavelmente não acarretaria grandes mudanças de qualidade e conservabilidade.

Não foram constatadas alterações significativas no teor de SST dos caquis armazenados. Os caquis apresentaram teor de SST na faixa de 13 a $16^{\circ}$ Brix, e as frutas submetidas a 24 horas de resfriamento alcançaram valores extremos e significativos aos 21 dias (superior) e aos 35 dias (inferior) de armazenamento em AC (Figura 3). Os demais tratamentos mantiveram um menor padrão de variação. Na maio- ria dos frutos colhidas em estádio pré-climatérico, independente da refrigeração ou não, observa-se incremento do conteúdo de SST ocasionado pela conversão de moléculas insolúveis para solúveis e/ou pela síntese (NEVES, 2002).

Em trabalhos com caqui 'Fuyu' colhidos na região da Serra do Rio Grande do Sul, Rinaldi et al. (1998) e Neves (2002) verificaram aumento do conteúdo de SST durante o armazenamento, resultados contrários aos encontrados neste experimento. Além das condições edafoclimáticas em que os frutos foram produzidos, o estádio de maturação no momento da colheita, bem como as diferenças entre condições de armazenamento possivelmente podem ter contribuído para essa contradição.

A ATT e SST dos caquis não apresentaram grandes alterações, demonstrando não serem bons indicativos da avaliação do processo de amadurecimento e qualidade pós-colheita. Provavelmente esses índices não mantêm uma relação intrínseca ao efeito fisiológico do resfriamento.

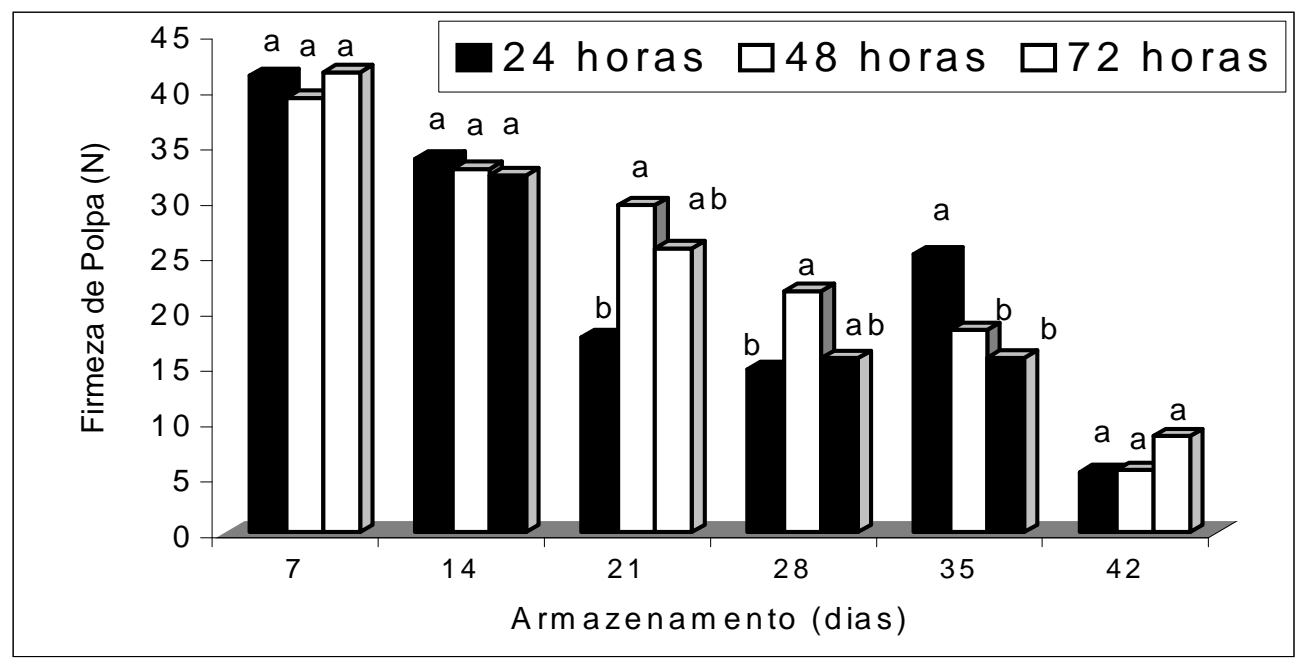

FIGURA 1 - Firmeza de polpa de caquis submetidos a 24, 48 e 72 horas de refrigeração antecedendo o armazenamento em AC, durante 42 dias mais 3 dias de vida de prateleira. Letras distintas na mesma coluna, diferem significativamente entre si, pelo teste de Tukey, ao nível de 5\% de probabilidade. 


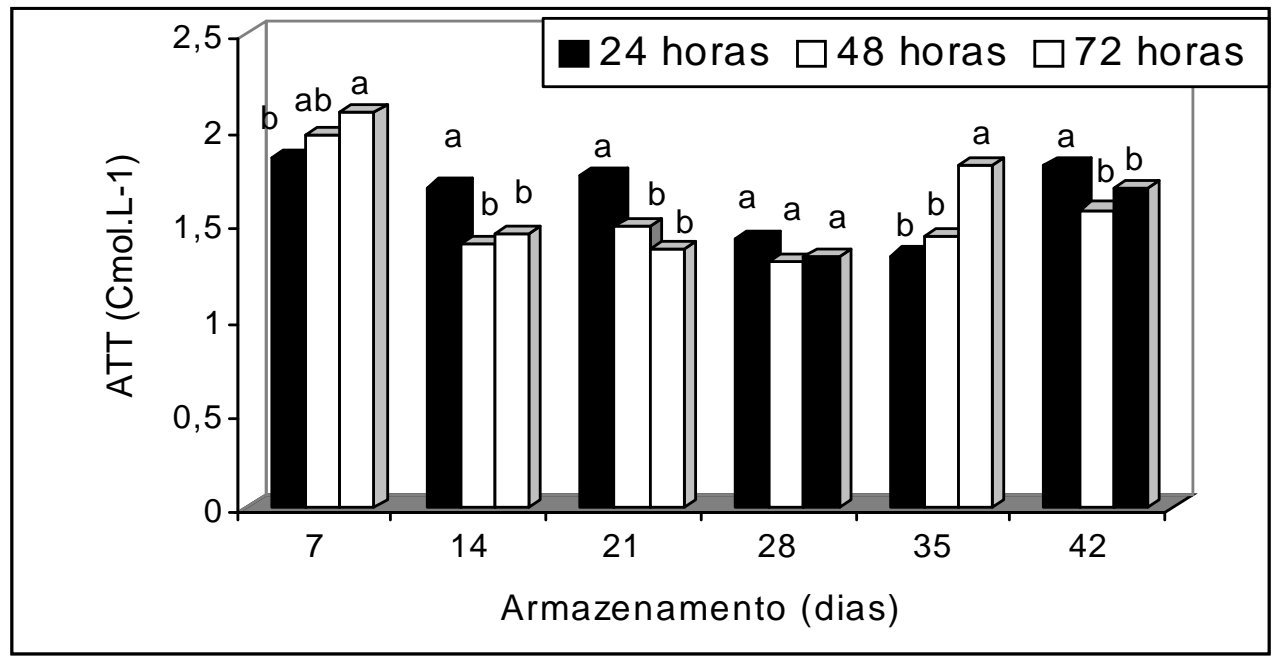

FIGURA 2 - ATT de caquis submetidos a 24, 48 e 72 horas de refrigeração antecedendo o armazenamento em AC, durante 42 dias, mais 3 dias de vida de prateleira. Letras distintas na mesma coluna diferem significativamente entre si, pelo teste de Tukey, ao nível de $5 \%$ de probabilidade.

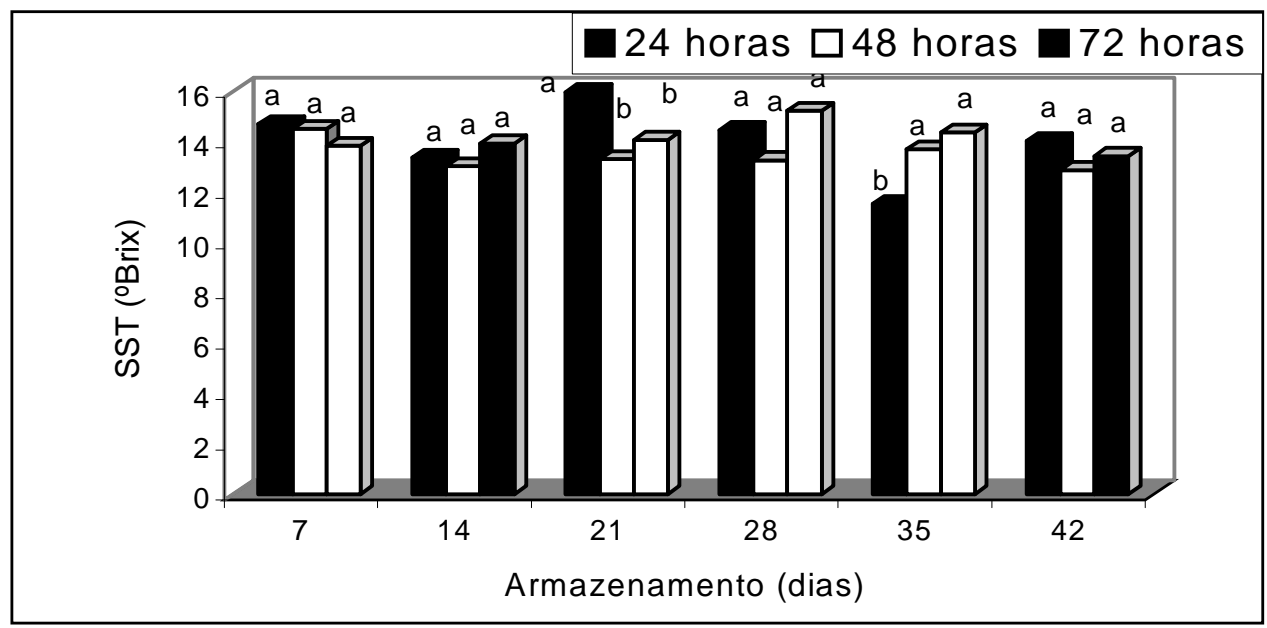

FIGURA 3 - SST de caquis submetidos a 24, 48 e 72 horas de refrigeração antecedendo o armazenamento em AC, durante 42 dias, mais 3 dias de vida de prateleira. Letras distintas na mesma coluna diferem significativamente entre si, pelo teste de Tukey, ao nível de 5\% de probabilidade.

Em relação à coloração da casca, observa-se na Figura 4 que houve uma pequena redução nos valores de $h$ com o avanço do período de armazenamento em $\mathrm{AC}$, nos frutos que receberam 24 e 72 horas de refrigeração, até o $21^{\mathrm{a}}$ dia de armazenamento. Aos 28 dias, o valor de $h$ volta a aumentar, depois repete a queda até os 42 dias de armazenamento. Apesar de os caquis submetidos a 48 horas de refrigeração apresentarem maior de- senvolvimento da coloração alaranjada aos 7 dias de armazenamento, houve elevação do valor de $h$ até o $28^{\circ}$ dia; a partir daí, houve evolução da coloração, refletindo na redução nos valores de $h$. Esses valores demonstram que o desenvolvimento da coloração dos caquis tratados variou com os períodos de armazenamento, não apresentando uma tendência explícita ao efeito dos tratamentos. 


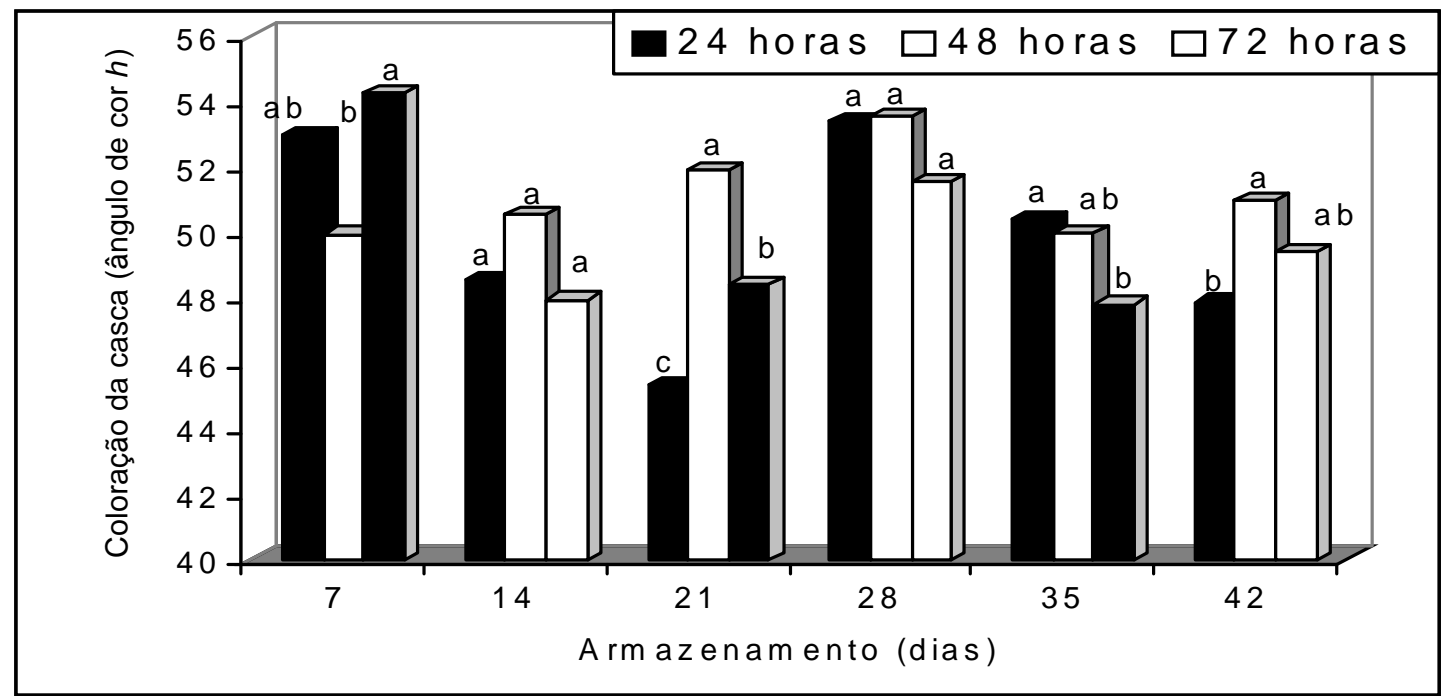

FIGURA 4 - Coloração de caquis submetidos a 24, 48 e 72 horas de refrigeração antecedendo o armazenamento em AC, durante 42 dias, mais 3 dias de vida de prateleira. Letras distintas na mesma coluna diferem significativamente entre si, pelo teste de Tukey, ao nível de $5 \%$ de probabilidade.

Em relação ao escurecimento da epiderme dos frutos, constatou-se que a partir de 7 dias de armazenamento todos os frutos apresentaram algum nível de escurecimento da epiderme, independente do tratamento efetuado (Tabela 1). O escurecimento evoluiu de forma crescente com avanço do período de armazenamento; entretanto, não foram constatadas diferenças significativas no nível de escurecimento entre os tratamentos efetuados. Vale ressaltar que não foram encontrados frutos que apresentassem notas $7,8,9$ e 10 correspondentes a mais de $70 \%$ da epiderme com escurecimento, razão pela qual não foram apresentados os valores na Tabela 1. Kader (1985) observou que esse tipo de distúrbio está mais relacionado com a evolução da maturação e a diminuição dos níveis de polifenóis dos frutos. Brackmann et al. (1997) armazenaram caquis cv. Fuyu provenientes da mesma região do presente experimento em condições de AC durante 3 meses, sem a presença de escurecimento na saída da câmara, mas com $47 \%$ dos frutos com escurecimento após quatro dias de exposição à temperatura ambiente. Constatou-se que os frutos quando retirados da câmara fria não apresentam grandes extensões de escurecimento epidérmico, mas quando submetidos ao período de simulação de comercialização por 3 dias em temperatura ambiente ( \pm $20^{\circ} \mathrm{C}$ e $75 \pm 5 \%$ UR), desencadeiam o surgimento do escurecimento em novos pontos, não observados na retirada da câmara. Provavelmente esse distúrbio seja estimulado pela alta atividade metabólica e produção de etileno, que associadas ao aumento da concentração do $\mathrm{O}_{2}$, desencadeiam reações oxidativas das enzimas fenólicas, refletindo diretamente nos níveis de escurecimento encontrados. Esse distúrbio pode inviabilizar a comercialização dos frutos, em especial para a exportação aos mercados mais exigentes, onde a porcentagem acima de $1 \%$ de escurecimento na epiderme de caqui cv. Fuyu já desqualifica o produto, restringindo sua comercialização (NEVES, 2002). 
TABELA 1 - Grau de escurecimento da epiderme (\%) de caquis cv. Fuyu, três dias após a retirada do armazenamento com condições de atmosfera controlada $\left(0 \pm 0,5^{\circ} \mathrm{C}, 95 \pm 3 \%\right.$ de $\mathrm{UR}, 8 \%$ de $\mathrm{CO}_{2}$ e $2 \%$ de $\left.\mathrm{O}_{2}\right)$, de acordo com escala visual de notas, em que $0=$ sem escurecimento, $1=1-10 \%, 2=11-20 \%, 3=21-30 \%, 4=31=40 \%, 5=41$ $50 \%$ e $6=51-60 \%$ de escurecimento da epiderme. 2002 .

\begin{tabular}{|c|c|c|c|c|c|c|c|}
\hline \multirow{2}{*}{ Variáveis } & \multirow{2}{*}{$\begin{array}{c}\text { Tratamentos } \\
\text { (horas de refrigeração) }\end{array}$} & \multicolumn{6}{|c|}{ Armazenamento (dias) } \\
\hline & & 7 & 14 & 21 & 28 & 35 & 42 \\
\hline \multirow{3}{*}{ Nota 0} & 24 horas & $97,63 a^{*}$ & $15,72 \mathrm{a}$ & $13,01 \mathrm{a}$ & $1,64 \mathrm{a}$ & $1,64 \mathrm{a}$ & $0 \mathrm{a}$ \\
\hline & 48 horas & $93,30 \mathrm{a}$ & $25,44 \mathrm{a}$ & $10,00 \mathrm{a}$ & $0 \mathrm{a}$ & $1,64 \mathrm{a}$ & $1,64 \mathrm{a}$ \\
\hline & 72 horas & $88,39 \mathrm{a}$ & $6,09 \mathrm{a}$ & $26,52 \mathrm{a}$ & $1,64 \mathrm{a}$ & $1,64 \mathrm{a}$ & $0 \mathrm{a}$ \\
\hline \multirow{3}{*}{ Nota 1} & 24 horas & $3,05 \mathrm{a}$ & $53,50 \mathrm{a}$ & $67,70 \mathrm{a}$ & $36,60 \mathrm{a}$ & $32,78 \mathrm{a}$ & $25,44 \mathrm{a}$ \\
\hline & 48 horas & $7,24 \mathrm{a}$ & $56,84 \mathrm{a}$ & $53,35 \mathrm{a}$ & $25,44 a$ & $36,45 a$ & $23,03 \mathrm{a}$ \\
\hline & 72 horas & $12,30 \mathrm{a}$ & $50,00 \mathrm{a}$ & $43,16 \mathrm{a}$ & $15,72 \mathrm{a}$ & $28,55 \mathrm{a}$ & $36,60 \mathrm{a}$ \\
\hline \multirow{3}{*}{ Nota 2} & 24 horas & 0 & $29,67 \mathrm{a}$ & $13,73 a$ & $43,16 \mathrm{a}$ & $29,67 \mathrm{a}$ & $43,16 a$ \\
\hline & 48 horas & 0 & $16,36 \mathrm{a}$ & $4,52 \mathrm{a}$ & $39,86 a$ & $42,66 \mathrm{a}$ & $33,26 \mathrm{a}$ \\
\hline & 72 horas & 0 & $23,03 \mathrm{a}$ & $15,72 \mathrm{a}$ & $26,52 \mathrm{a}$ & $26,20 \mathrm{a}$ & $30,00 \mathrm{a}$ \\
\hline \multirow{3}{*}{ Nota 3} & 24 horas & 0 & $0 \mathrm{a}$ & $0 \mathrm{a}$ & $13,01 \mathrm{~b}$ & $29,67 \mathrm{a}$ & $23,18 \mathrm{a}$ \\
\hline & 48 horas & 0 & $0 \mathrm{a}$ & $13,01 \mathrm{a}$ & $29,67 \mathrm{ab}$ & $16,36 \mathrm{a}$ & $27,96 a$ \\
\hline & 72 horas & 0 & $4,98 \mathrm{a}$ & $13,01 \mathrm{a}$ & $36,60 \mathrm{a}$ & $32,78 \mathrm{a}$ & $33,26 a$ \\
\hline \multirow{3}{*}{ Nota 4} & 24 horas & 0 & 0 & $0 \mathrm{a}$ & $1,64 \mathrm{a}$ & $1,64 \mathrm{a}$ & $1,64 \mathrm{a}$ \\
\hline & 48 horas & 0 & 0 & $7,24 \mathrm{a}$ & $1,64 \mathrm{a}$ & $0 \mathrm{a}$ & $1,64 \mathrm{a}$ \\
\hline & 72 horas & 0 & 0 & $0 \mathrm{a}$ & $10,00 \mathrm{a}$ & $3,05 \mathrm{a}$ & 0 \\
\hline \multirow{3}{*}{ Nota 5} & 24 horas & 0 & 0 & $0 \mathrm{a}$ & 0 & 0 & $1,64 \mathrm{a}$ \\
\hline & 48 horas & 0 & 0 & $1,64 \mathrm{a}$ & 0 & 0 & $0 \mathrm{a}$ \\
\hline & 72 horas & 0 & 0 & $0 \mathrm{a}$ & 0 & 0 & $0 \mathrm{a}$ \\
\hline \multirow{3}{*}{ Nota 6} & 24 horas & 0 & 0 & 0 & $0 \mathrm{a}$ & 0 & 0 \\
\hline & 48 horas & 0 & 0 & 0 & $0 \mathrm{a}$ & 0 & 0 \\
\hline & 72 horas & 0 & 0 & 0 & $4,98 \mathrm{a}$ & 0 & 0 \\
\hline
\end{tabular}

*Letras diferentes na coluna indicam que houve diferença significativa ao nível de $5 \%$ de probabilidade.

\section{CONCLUSÕES}

Diferentes períodos de refrigeração de caquis antes de serem armazenados em AC nas câmaras comerciais não proporcionam diferenças na qualidade e potencial de conservação dos frutos estudados. A firmeza de polpa, SST e o escurecimento da epiderme não foram influenciados por nenhum tratamento. Os frutos apresentaram primeiros sintomas de escurecimento da epiderme aos 7 dias de armazenamento, independente do tratamento adotado.

\section{REFERÊNCIAS BIBLIOGRÁFICAS}

BEN-ARIE, R. Commercial quality of "Fuyu" persimmon. Postharvest Biology and Technology, Amsterdam, v. 14, n. 3, p. 311-317, 1995.

BEN-ARIE, R.; ZUTKHI, Y. Extending the storage life of "Fuyu" persimmon by modifiedatmosphere packaging. HortScience, Alexandria, v. 27 , n. 7, p. 811-813, 1992. 
BRACKMANN, A.; DONAZZOLO, J. Armazenagem de caqui. In: ENCONTRO NACIONAL SOBRE FRUTICULTURA DE CLIMA TEMPERADO, 3., 2000, Fraiburgo. Anais... Fraiburgo: EPAGRI, 2000. p. 99-102.

BRACKMANN, A.; MAZARO, S. M.; SAQUET, A. A. Frigoconservação de caquis (Diospyros kaki, L.) das cultivares Fuyu e Rama Forte. Ciência Rural, Santa Maria, v. 27, p. 561-565, 1997.

BRACKMANN, A.; SAQUET, A. A. Efeito da temperatura e condições de atmosfera controlada sobre a conservação de caqui (Diospyros kaki L.). Ciência Rural, Santa Maria, v. 25, n. 3, p. 375378, 1995.

CRISOSTO, C. H.; JOHNSON, R. S.; DEJONG, T. Orchard factors affecting postharvest stone fruit quality. HortSciense, Alexandria, v. 32, n. 5, p. 820-823, 1997.

DANIELI, R. Retardamento da colheita e conservação de caquis (Diospyros kaki, L) cv. Fuyu. 2000. 52 f. Dissertação (Mestrado em Ciências) - Faculdade de Agronomia Eliseu Maciel, Universidade Federal de Pelotas, Pelotas, 2000.

FERRI, V. C. Controle da maturação e conservação de caquis (Diospyros kaki, L) cv. Fuyu. 2000. 103 f. Tese (Doutorado em Agronomia) - Faculdade de Agronomia Eliseu Maciel, Universidade Federal de Pelotas, Pelotas, 2000.

HELBIG, V. E. Ponto de colheita e tempo de armazenamento refrigerado na conservação de ameixas (Prunus salicina, L) cvs. Pluma 7 e Wade.

In: CONGRESSO BRASILEIRO DE CIÊNCIA E TECNOLOGIA DE ALIMENTOS, 16., 1998, Rio de
Janeiro, RJ. Anais... Rio de Janeiro: SBCTA, 1998. v. 2, p. 110.

KADER, A. A. An overview physiological and biochemical basis of CA effects on fresh horticultural crops. In: BLAKENSHIP, S. M. (Ed.). Controlled atmospheres for storage and transport of perishable agricultural commodities. Raleigh: [s.n.], 1985. p. 1-9.

KAWADA, K. Use of polymeric films to extend postharvest life and improve marketability of fruits and vegetables. In: . Unipack: individually wrapped storage of tomatoes, oriental persimmons and grapefruit. [S.1.: s.n.], 1982. p. 87-99.

MACRAE, A. E. Development of chilling injury in new Zealand grown Fuyu persimmon during storage. New Zealand Journal of Experimental Agriculture, Auckland, n. 15, p. 333-344, 1987.

MITCHAM, J. E.; CRISOSTO, C. H.; KADER, A. A. Recommendations for maintaining postharvest quality. Davis: University of California, 1998. 120 p.

NEVES, L. T. B. C. Atmosfera modificada e absorção de etileno no armazenamento refrigerado de caquis (Diospyros kaki, L) cv. Fuyu. 2002. 70 f. Dissertação (Mestrado em Ciências) - Faculdade de Agronomia Eliseu Maciel, Universidade Federal de Pelotas, Pelotas, 2002.

RINALDI, M. M.; FERRI, V. C.; ROMBALDI, C. V. Frigoconservação de caquis (Diospyros kaki, L) cv. Fuyu, em atmosfera modificada. In: CONGRESSO BRASILEIRO DE CIÊNCIA E TECNOLOGIA DE ALIMENTOS, 16., 1998, Rio de Janeiro, RJ. Anais... Rio de Janeiro: SBCTA, 1998. v. 2, p. 415-420.

ROMBALDI, C. V. Armazenagem de caqui. Jornal da Fruta, São Paulo, n. 232, p. 4, 1999. 